Central Washington University

ScholarWorks@CWU

Library Scholarship

James E. Brooks Library

$11-2020$

\title{
No Textbook Cost General Education Pathway: An Effort to Increase Retention at Central Washington University
}

\author{
Maura Valentino \\ Central Washington University, maura.valentino@cwu.edu \\ Geri Hopkins \\ Central Washington University, hopkins@cwu.edu
}

Follow this and additional works at: https://digitalcommons.cwu.edu/libraryfac

Part of the Educational Methods Commons, Higher Education Commons, and the Scholarly Communication Commons

\section{Recommended Citation}

Valentino, M. and Hopkins, G. (2020), "No textbook cost general education pathway: an effort to increase retention at Central Washington University", Reference Services Review, Vol. ahead-of-print No. ahead-ofprint. https://doi.org/10.1108/RSR-03-2020-0015

This Article is brought to you for free and open access by the James E. Brooks Library at ScholarWorks@CWU. It has been accepted for inclusion in Library Scholarship by an authorized administrator of ScholarWorks@CWU. For more information, please contact scholarworks@cwu.edu. 
No Textbook Cost General Education Pathway: An Effort to Increase Retention at Central Washington University

At Central Washington University (CWU), as at many institutions of higher education, student retention is an issue of increasing concern. CWU President James Gaudino has made growing the first-year to second-year student retention rate, from 71 percent to 80 percent over the next five years one of CWU's top three goals. In addition, the high cost of textbooks and other educational materials presents an ever-increasing financial burden on students, negatively impacting student success and retention. This financial burden is most profound on students with limited economic means, making the high cost of textbooks a competitive disadvantage and a social justice issue. The authors envisioned the No Textbook Cost General Education Pathway project (the project) to help address this disparity and increase retention by replacing costly textbooks with free Open Educational Resources and library resources (OER). The project was funded with a $\$ 36,000$ grant from the Washington Student Achievement Council, resulting in 26 courses converting to OER and providing multiple textbook cost-free pathways through CWU's newly redesigned General Education Framework (GEF).

\section{Literature Review}

A review of the literature relating to the adoption of OER by faculty at the university level revealed several points of interest relating to the project. The first refers to faculty concerns regarding the use of OER to replace traditional textbooks. Faculty who are unfamiliar with OER may have concerns over the quality of OER materials when compared with traditional textbooks. However, Allen \& Seaman (2014) found two survey studies of faculty who used OER. In one case, 70 percent of faculty surveyed found OER material to be of the same or superior quality to traditional materials, and the other 90 percent reported a similar opinion. Another study by Stout (2018) found that OER materials are simpler to navigate and better aligned to learning outcomes. It should also be noted that faculty are often comfortable using traditional pedagogies, and may also rely on supplemental materials that publishers offer as incentives to professors to require their textbooks, as noted by Lederman (2018). Martin et. al. (2017) note that faculty are willing to use OER if they are of sufficient quality.

However, while faculty attitudes regarding the adoption of OER are a vital factor to consider when designing and implementing OER programs, there is literature that supports the need to reduce the high cost of learning materials and the link between OER and student retention. For example, Billings, Hutton, 
Schafer, Schweik, and Sheridan (2012) note that students do not buy the textbook, and refrain from taking classes that require expensive textbooks. Jhangiani (2018) states that students use various methods to find the information found in the textbooks, including sharing books, photocopying or scanning relevant parts of the book or buying older editions, rather than buying the expensive textbook. Brandi et. al. (2019) add that students in OER classes access their materials before the class begins and find the access easier. Additionally, a study conducted by Griffiths et al. (2018) reveals that a reduction in the cost of learning materials contributes to restoring and even improving student retention. "The [Achieving the Dream] study indicates that, based on two years of implementation across scores of colleges, OER can be an important tool in helping more students - and particularly low-income and underrepresented students - afford college, engage actively in their learning, persist in their studies, and ultimately complete [graduation]." Student interest in Open Educational Resources can also be seen in an OER analysis by Lederman (2018). He notes that colleges that added an OER designation to the catalog resulted in 24 percent of student registrants sign up exclusively for OER courses because it would save them money.

The literature also supports the use of financial incentives for faculty to replace textbooks with OER. Preville (2019) asserts that using financial incentives to encourage faculty to use or create OER is a winning strategy, adding that faculty do not otherwise feel rewarded for pedagogical innovation. Lederman-2 (2018) notes that one of the reasons for the great success of OER at Pierce College was the provision of incentives of $\$ 1,500$ for faculty to create their own OER.

\section{Background}

In 2017, the authors initiated an OER Task Force to discuss options and goals for OER adoption by CWU faculty. Work began by conducting campuswide presentations on OER to encourage its adoption. As noted in the literature review above, a proven method of expanding the use of OER on college campuses is to incentivize faculty to eliminate expensive textbooks and replace them with OER.

Based on the success of a similar project initiated by Valentino at a different university in the Pacific Northwest, Valentino saw an opportunity to obtain grant funding to conduct a similar program at CWU. When the Washington Student Achievement Council released a call for proposals in 2018 for the Washington Open Educational Resources Grant Pilot Program (https://wsac.wa.gov/oer-grants), the authors developed a proposal requesting $\$ 36,000$ in grant funding to provide 
stipends of $\$ 1,000$ each to faculty to develop new OER or use existing OER, rather than traditional expensive textbooks. Two stipends of $\$ 1,500$ would be made available for faculty who wished to create a new OER, rather than using existing OER. Before the grant proposal could be submitted, the university required a pregrant review by the CWU Grants Office. After some negotiation, the Grants Office agreed to waive the indirect costs, which allowed for 27 stipends of $\$ 1,000$ plus benefits to be offered. The grant application was submitted, and the Washington Student Achievement Council funded the grant for $\$ 36,000$.

Another essential aspect in the planning phase of the project included targeting courses for conversion to OER, given that only 27 stipends would be available. The authors focused on courses contained in CWU's newly redesigned General Education Framework (GEF) to provide a complete path through the framework using OER. The GEF includes several components, with a First-Year Experience that consists of a First-Year Seminar, an Introductory Writing course, and a Quantitative Reasoning course. During their second year, students select a course from each of seven Areas of Knowledge. Within each Knowledge Area, students can choose various pathways, such as Social Justice or Sustainability, and focus on that Pathway. If a student completes 5 courses in any pathway, they receive a Milestone in that pathway. Finally, each student completes a Culminating Experience as a senior. For more information on the GEF, see Appendix A. The redesign of the GEF, which included dozens of new courses to be implemented in the Fall of 2019, presented the perfect opportunity to incentivize faculty to replace expensive textbooks with cost-free OER and library resources.

\section{Methodology}

As noted above, the objective of the No Textbook Cost General Education Pathway project was to provide CWU students an opportunity to complete the new GEF without having to purchase textbooks. Expectations were that OER materials would be widely available in many areas of study within the GEF, as many previous OER projects have targeted similar high-enrollment, commonly taught courses. Academic libraries often have resource guides on OER, including the University of Michigan, the University of Oklahoma, and many others. OpenStax and OER Commons also target general education courses. Two stipends providing an additional $\$ 500$ would be offered to faculty for creating their own OER if they were selected to participate in the project. Priority would be given to high enrollment courses that would replace the most expensive textbooks, and consideration would be given to ensuring that courses from each Knowledge Area 
and Pathway were included in the chosen proposals. A formal rubric was never created, and in the end, was not needed.

One of the initial challenges the authors faced in implementing the program related to creating a workable timeline. In December 2018, the authors were notified by the grantee that all grant funds had to be expended before September 30,2019 , leaving a time to completion of only nine months. The fact that most CWU faculty are not present on campus during the summer months added additional time pressure to the project. In the end, the faculty had three weeks to submit their applications and ten weeks to select the OER used in the program. The timeline is part of the Call for Proposals (https://digitalcommons.cwu.edu/libraryfac/81/).

After finalizing the timeline, the next step was informing and educating the faculty about OER and the grant opportunity. We offered two presentations explaining the grant and the goals of the program, emphasizing the significant financial burden that high-cost textbooks impose on students, and the social justice implications of a two-tier classroom that advantages students who can afford the textbook over those who cannot. While most faculty were aware of the high cost of textbooks based on their own educational experiences, many had not considered the social justice aspects relating to textbook costs. The presentations also explained the application process. Additionally, the authors met with the Chair of the English department and several English department faculty members to encourage participation, as the English 101 course forms a crucial component of the GEF and is one of only two choices to complete the program's Academic Writing I requirement.

The next step was the call for proposals. The authors sent out the call for proposals to all CWU faculty seeking applicants who would be teaching in the new GEF for the 2019-2020 academic year. The authors sought input from the OER Task Force members representing each of CWU's the university's four colleges, and encouraged faculty from their departments to apply for stipends. The CWU General Education Committee also has representatives from each college, each of which was asked to recommend fellow faculty to apply. Additional notifications were sent to the liaison to the Faculty Senate General Education Committee to encourage faculty to apply.

The call for proposals quickly produced $50 \%$ of the needed 27 applicants, with a promising spread of prospective courses, but as the days progressed, the submissions slowed. As the application deadline approached, there were not yet 
enough courses to produce a pathway through the new GEF. There were still three Knowledge Areas that needed at least one course to complete at least one Pathway through the GEF. To remedy this situation, the authors checked the schedule of classes to find faculty who would be teaching in these knowledge areas and reached out directly to them. This effort resulted in applications that provided critical coverage for the program.

Exactly 27 submissions were received by the deadline, which allowed the grant team to bypass creating a rubric for a selection process. All 27 courses were accepted. Four were from the First-Year Experience, one in Academic Writing I, two in Quantitative Reasoning, three in Academic Writing II, three in the Physical and Natural World, three in Science and Technology, five in Individual and Society, two in Community, Culture, and Citizenship, three in Global Dynamics, three in Creative Expression and one in Humanities. Some courses fulfilled the requirement for more than one Pathway, but never more than one Knowledge Area. The next step was to locate OER and library materials to replace existing course materials for each of the 27 courses. Throughout the process, two participants withdrew from the program, due the fact that they were no longer teaching the course, and another joined the cohort, resulting in 26 courses being converted to OER. In addition, only one participant created their own OER textbook receiving the extra $\$ 500$ stipend designated for this work. Appendix B contains information describing how the 26 courses fit into the GEF.

Of the 27 applications, ten faculty had already selected OER content and 17 required assistance. The authors split these 17 courses between them and provided faculty with potential OER for use in their courses. Several of these faculty chose resources other than those suggested. For example, the Social Demographic instructor determined that the standard textbooks were too advanced and used two websites, Rand.org and Worldbank.org, instead. Both sites have ample resources, including the most recent research. The instructor for Introductory Statistics found the Open textbooks too math-heavy and chose YouTube videos instead. The instructor for Controversies in Nutrition selected an open-source textbook supplemented with scholarly articles.

The team also divided the other ten courses and followed up with instructors should they need additional help or resources. For the ten professors who had already found resources without the authors' assistance, only one responded when asked if anything else was needed. The Controversial Issues in Sports and Health instructor required scholarly articles on controversies in sports. The authors 
fulfilled this request by providing options to view scholarly articles on controversies in sports, including steroids, doping, and adolescent risks.

While the course materials were being compiled, Professor Valentino wrote two assessment surveys, one for stipend recipients focusing on how easy or difficult it was to find appropriate OER materials, and one for their students. The student survey focuses on:

- Their opinions of using OER to replace traditional textbooks or other materials

- Ease or difficulty to access the materials

- Additional comments on textbook costs

These surveys were based on OER surveys used in other projects. Still, they were reduced to 11 questions for students and 8 for faculty, to enable quick completion.

\section{Results}

The authors achieved the initial goal for the project of creating at least one complete cost-free textbook Pathway through the GEF. If all OER courses available are combined with the courses converted as a part of this project, over 4,000,000 separate pathways now exist without textbook costs, providing students with a great deal of flexibility in choosing their path through the Gen Ed requirements.

Students can also earn a Milestone in a Pathway by completing five courses in one Pathway in the Gen Ed curriculum. At the outset of the project, it was hoped that students would be able to achieve at least one Milestone using converted OER courses. Believing that faculty in the Social Justice Pathway would be most inclined to join efforts for a socially just classroom, the authors hoped for more Social Justice faculty to convert to OER. This would have allowed their students to complete the Social Justice Milestone using only OER courses. As only four Social Justice faculty applied, this goal was not achievable. However, if all the OER courses currently available campus-wide are included, and not just those contained in this project, a student can complete a Milestone in five of six available Pathways.

Twenty-three faculty completed the faculty survey. Most of the faculty found the materials easy to find, while only two rated the difficulty a 7 out of 10 (10 being most difficult). This difficulty came from having to search many different sites. Most found the materials of high quality. Faculty reported using 
Open textbooks, articles from the library, Open Access articles, eBooks from the library, websites, and government resources. Several faculty were OER advocates before this grant cycle, but most were converts after actually teaching with OER. These results are in line with Hilton et al survey of 42 faculty members. The study found that faculty found OER resources to be equivalent or better.

Table 1: Resources Used by Faculty

Many faculty members were familiar with available resources, but others used the library website, OER websites, Lumen Learning, PubMed, and others to find content.

\section{Table 2: Where Faculty Found Resources}

Most faculty answered yes to the question, "Are you encouraged by this transition to OER to consider using Open and/or library materials in any other course? Fifteen faculty answered yes, only one answered no. Three responded that they already used OER in other courses.

The student survey also yielded positive results. Most of the students were quickly able to access the materials. For those who were not able to access materials, the reasons had nothing to do with the OER resources. Nearly ninety percent would choose an OER course over a non-OER course. Forty-five percent reported textbook costs impacted the courses their choices. Fifty-six percent decided not to buy the book due to textbook cost, and thirty-seven of those students thought it affected their grades negatively. Students used many methods to obtain the information in the textbook without purchasing the textbook, including borrowing a copy of the book, buying an older edition, and using other resources to learn the material. Several students commented that the professor didn't use the book, so not having it made little difference. In the Open Comments section, students reiterated that many professors do not use the book. Again, these results are similar to previous studies. Feldstein et al. and Hilton et al. studies both found that students recommend OER to fellow classmates and found OER easy to use and more up-to-date, notes Hilton (2016).

Cost savings to students was calculated by choosing the highest and lowest cost of each textbook that was replaced, and then multiplying the results by the number of students in those course sections. This process yielded the highest possible cost savings if each student bought the most expensive copy of the book and the lowest cost savings if each student purchased the least expensive copy of 
the book. Estimated savings for 5200 students calculated to between $\$ 360,000$ and $\$ 600,000$ (see Appendix C.)

The response on campus to the project has been overwhelmingly positive. After presenting the grant to the Faculty Senate Executive Committee, the Provost then asked the authors to present to the Provost's Council. Between the dates of these two presentations, the president of the university gave his State of the University address where he once more emphasized that first to second-year retention was a top CWU priority. As the link between OER and student retention is evident in the literature, the OER presentation was adapted for the president's goal, resulting in the Provost charging the Dean of Libraries with creating a campus-wide, three-year Low-cost Textbook Initiative. As this project is still in the last quarter of the first year, assessment of this project on retention would be a future study. With the pandemic, assessment of this aspect of the project is impossible. After the first year, the grades for OER and non-OER sections of the same course will be compared to see if there is improved pedagogy.

\section{Lessons Learned and Limitations}

One of the most significant challenges while administering the program related to obtaining all of the information required from faculty before their stipends could be processed. The project required that the recipient choose the OER or other materials and incorporate these materials into the syllabus and the Canvas course. However, Winter and Spring 2020 Canvas courses were not yet available to the faculty for adaptation, creating a delay in meeting this requirement. The recipients were also required to complete an anonymous post-course survey, and agreed to present a post-course survey to their students. According to the terms of the grant, the stipends had to be completed by September 2019, before all student surveys could be completed. The final report for the granting agency can be found at (https://digitalcommons.cwu.edu/libraryfac/80/).

In addition to incentivizing faculty to adopt OER, the team also sought an OER course designation in CWU's Class Search software. The designation would allow students to easily distinguish OER course from those with standard commercial content. A solution request to Information Services indicated a simple modification in the software, but a conflict arose as the authors attempted to move forward on the designation. A presentation to The Provost's Council met with enthusiasm about the solution. However, the Academic Department Chairs Organization (ADCO) was not in favor of an OER course designation and is still in negotiation with CWU faculty and administration. A short-term solution, 
currently in use, allows faculty to add "Zero textbook costs" as a Note in the course textbook adoption software, but does not allow for direct discovery by students. Instead, students must select each course individually to see the Zerocost Note.

\section{Next Steps}

The enthusiastic support of CWU's Dean of Libraries and Provost's Office have proved very helpful at all stages of the project, and several next steps have been initiated as a result of this project. First, it was agreed upon by most stakeholders that adding an official course designation to the Class Search system is an essential step in OER efforts. It is hoped that continued outreach to faculty will help find consensus on this issue. To this end, all future OER presentations to the campus community will address this issue.

Secondly, the Provost has awarded the library $\$ 15,000$ to provide additional stipends for faculty as part of a new Affordability Initiative currently in progress. including the development of a three-year plan to further reduce textbook costs as much as possible.

Finally, while the data from the surveys has been briefly reviewed, further analysis is planned, as well as data from the registrar's office comparing grades of OER courses with non-OER courses, similar to what was done at University of Georgia, as described by Colvard et. al. (2018) The authors have hopes for a follow-up article.

\section{Conclusion}

Overall, the No-Cost Textbooks General Education Pathway project has been a great success and has directly led to a change of the paradigm on campus. The Brooks Library has allocated funds for another round of incentive grants for faculty, and is developing a three-year plan to reduce textbook costs campus-wide. Even if some faculty still question the quality of OER materials, continued education and close coordination with faculty advocates will hopefully help the OER program to prosper, reducing textbook costs and promoting social equity for Central Washington University students. 
Running Head: NO TEXTBOOK COSTS GEN ED PATHWAY 
Running Head: NO TEXTBOOK COSTS GEN ED PATHWAY

References 